\title{
SOBRE A NATURALIZAÇÃO DAS INJUSTIÇAS E IDEOLOGIA NA CIÊNCIA: ANÁLISE CRÍTICA DE UM TEXTO DA REVISTA NATURE ${ }^{1}$
}

\author{
Maíra Tavares Mendes²
}

Resumo: O trabalho analisa o discurso de um texto científico sobre comportamento de macacos-prego, o qual discute o senso de justiça em primatas não humanos, utilizando como parâmetros descritivos das reações dos animais conceitos da economia clássica liberal. Discutimos o papel da ideologia (ou superestruturas) na explicação da realidade pelos cientistas, em especial a polissemia do termo natural - assumindo tanto o sentido de relativo à natureza quanto o de algo conforme o esperado. Consideram-se as contribuições de Bakhtin, Marx, Engels, Gramsci e Gould para uma apreciação sobre o método diversa da postura empirista: postula-se que o método é uma mediação capaz de fazer da ciência um universal humano, ou seja, deve permitir que qualquer ser humano possa, compartilhados os requisitos de linguagem, chegar a conclusões em comum a partir do raciocínio de outro ser humano com o qual não possui qualquer outra semelhança.

Palavras-chave: Filosofia da ciência. Ideologia. Relação homem-natureza.

\section{NATURALIZING INJUSTICE AND IDEOLOGY IN SCIENCE: CRITICAL DISCOURSE ANALYSIS OF A TEXT FROM NATURE JOURNAL}

Abstract: The aim of this paper is to analyze the discourse of a scientific text on capuchin monkey's behavior, which discusses non-human primates' fairness sense with classic liberal economy concepts as parameters. Based on the contribution of Critical Discourse Analysis, we discuss the role played by ideology (conceived as superstructure) to conform reality explanations, particularly the polissemic term natural. The latter could be interpreted either as relative to the nature or as something expected. We consider the contributions of Bakhtin, Marx, Engels, Gramsci and Gould for a reflection on method other than the empiricist approach, assuming the method as mediation capable of making any human being who shares language requirements reach common conclusions.

Keywords: Philosophy of science. Ideology. Man-nature relationship.

\section{SOBRE LA NATURALIZACIÓN DE LA INJUSTICIA Y DE LA IDEOLOGÍA EN LA CIENCIA: ANÁLISIS CRÍTICO DE UN TEXTO DEL PERIÓDICO NATURE}

Resumen: El trabajo analiza el discurso de un texto científico sobre el comportamiento de los monos capuchinos, que aborda el sentido de la justicia en los primates no humanos, utilizando como parámetros descriptivos de las reacciones de los animales conceptos de la economía clásica liberal. Discutimos el papel de la ideología (o superestructuras) en la explicación de la realidad por los científicos, especialmente la polisemia del

\footnotetext{
1Texto modificado a partir de trabalho aprovado no V Encontro Regional de Educação, Marxismo e Emancipação Humana.

2 Doutoranda em Educação pelo Programa de Pós-Graduação em Educação da UERJ (bolsista FAPERJ).

Professora Assistente da Universidade Estadual de Santa Cruz, Ilhéus, Bahia, Brasil. mtmendes@uesc.br
} 
término natural - asumiendo tanto el sentido de relativo a la naturaleza cuanto o de algo según el esperado. Tenemos en cuenta los aportes de Bakhtin, Marx, Engels, Gramsci y Gould para una apreciación del método diverso de la postura empirista: postulamos que el método es una mediación capaz de hacer de la ciencia un universal humano, es decir, debe permitir a cualquier ser humano que pueda, desde los requisitos lingüísticos compartidos, llegar a conclusiones en comunes a partir del razonamiento de otro ser humano con quien no tiene ninguna similitud.

Palabras-llave: Filosofía de la ciencia. Ideología. La relación hombre-naturaleza.

\section{Introdução}

As redes sociais possuem a formidável virtude (ou o lamentável vício) de circular informações numa velocidade cada vez mais impressionante - fenômeno que tem sido conhecido pelo peculiar neologismo viralização - similares à rápida velocidade de reprodução de vírus, determinados conteúdos são multiplicados em instantes. Parece ter sido o caso do vídeo Macacos pagos desigualmente ${ }^{3}$. A cena, mostrada pelo cientista holandês radicado nos Estados Unidos Frans de Waal, dificilmente passa desapercebida por quem a assiste: trata-se de uma palestra proferida por De Waal sobre a noção de justiça em macacos. Ele mostra o trecho do vídeo de um experimento em que uma cientista (assumida como tal pela indumentária de laboratório) apresenta uma pedra a cada um dos dois macacos, presos em jaulas adjacentes transparentes (ou seja, podem ver e ser vistos um pelo outro). Cada macacoprego recebe, um por vez, uma pedra, que devolvem à cientista, no vídeo. O macaco da esquerda, após devolver a pedra, recebe um pepino. O da direita, ao fazer a mesma ação, recebe uma uva - o que parece perturbar o macaco da esquerda. A operação se repete, sendo que o macaco da esquerda devolve a pedra novamente à cientista, recebendo, outra vez, um pepino, e verifica que o parceiro recebeu, outra vez, uma uva. Visivelmente transtornado, o macaco da esquerda joga o pepino recebido na cientista, segura nas grades da jaula como quem se revoltasse, dá voltas no espaço reduzido da jaula, e, ao devolver a terceira pedra e obter mais uma vez o pepino, bate com as mãos no chão, arremessando novamente a fatia de pepino para fora.

Ao assistir o vídeo, o experimento do primatologista da Universidade de Emory, especialista em comportamento animal, depois de render algumas gargalhadas (sempre reiteradas ao compartilhar o vídeo com alguém), deixou-me intrigada. Procurei maiores informações sobre o projeto de pesquisa, já que a cena exibida permite as mais diversas conclusões, seja quanto ao comportamento de macacos, seja de seres humanos. O artigo mais acessível que consegui foi publicado em 2003, pela revista Nature: Monkeys reject unequal pay" ["Macacos rejeitam pagamento desigual, de autoria de Sarah F. Brosnam e Frans de Waal (outros eram regidos por restrições de acesso na Internet). É a partir da leitura desse texto citado que discuto a distinção entre homem e natureza, e as implicações dessa discussão para a ciência.

3 O vídeo Capuchin monkeys fairness experience, disponível no canal YouTube (http://www.youtube.com/watch?v=KSryJXDpZo), é um excerto de uma palestra concedida em 2011 por Frans De Waal para a fundação privada TED (Technology, Entertainment, Design). A palestra pode ser vista na íntegra, com legendas em português, no linque:

<http://www.ted.com/talks/lang/ptbr/frans_de_waal_do_animals_have_morals.html>. 


\section{Do método, ou a justiça dos macacos}

Bakhtin já afirmou, há quase um século, que todo signo é ideológico. A linguagem é produção social imersa em relações de poder (de classe, inclusive), em que os signos enquanto materialidade simbólica carregam sentidos históricos. A análise das condições de produção de determinados sentidos é preocupação da análise de discurso, que, em sua variante crítica (ACD - análise crítica de discurso), procura conceber o discurso de maneira tridimensional: como texto propriamente dito, como prática discursiva (produção, circulação e consumo textuais) e também como prática social (FAIRCLOUGH, 2001). A partir da leitura do texto de Brosnan e de Waal (2003), procurei analisar elementos que pudessem contribuir no debate sobre o discurso científico quanto ao estatuto do que é natural (no sentido de relativo à natureza). A própria polissemia do termo natural - compreendido tanto como adjetivo relativo ao que é próprio da natureza, quanto algo que seja conforme o esperado - é fundamental para o tratamento de determinadas considerações como universais entre seres humanos tanto quanto em outros animais (no caso, os macacos-prego).

O texto (BROSNAN; DE WAAL, 2003) consiste de 3 páginas da revista Nature, descrevendo os resultados mais conclusivos do estudo realizado. A estrutura do (sucinto) texto consiste de uma afirmação geral que contextualiza a discussão sobre o senso de justiça dos macacos, a partir de uma revisão de literatura. Curiosamente, boa parte dos trabalhos citados foram publicadas em revistas do mainstream da Economia (e, aqui, não falo em economia marxista) tais como Quarterly Journal of Economics, American Economic Review e Annales d'Economie et de Statistique. Os resultados são discutidos à luz dos testes estatísticos das hipóteses levantadas. Somente no final do artigo, em letra miúda não muito maior do que as miudíssimas letras das referências bibliográficas, consta o tópico do método empregado.

O par de cientistas inicia o trabalho pela seguinte afirmativa: "Durante a evolução da cooperação, pode ter se tornado crítico para os indivíduos comparar seus próprios esforços e recompensas com as dos outros" " (BROSNAN; DE WAAL, 2003, p.297). O núcleo central dessa sentença consiste da expressão "pode ter se tornado crítico" - o sujeito dessa ação - a possibilidade (indicando uma abertura quanto à certeza) de ter se tornado crítico é a comparação entre esforços e recompensas. Haveria a possibilidade de que tenha se tornado crítico que indivíduos comparem seus próprios esforços e recompensas. Quem enuncia a frase não se compromete com a criticidade da comparação dos indivíduos, mas essa enunciação tem como pressuposto lógico que indivíduos comparam esforços e recompensas. E, em se tratando de um estudo de primatologistas, esses indivíduos não são (apenas) humanos, ou seja, há a atribuição de um caráter natural, que inclui macacos-prego e humanos, no mínimo, à comparação de esforços e recompensas entre indivíduos. A esse pressuposto implícito voltaremos, mais adiante.

Dada como fato consumado a comparação entre indivíduos de seus esforços e recompensas, o texto afirma que "reações negativas podem ocorrer quando as expectativas são violadas" (BROSNAN; DE WAAL, 2003, p. 297). A ênfase, aqui, está nas reações, que são o sujeito da oração, e não de qualquer tipo - a adjetivação é reações negativas. A característica negativa não é definida, qualificada ou discutida - não está claro se é negativa em contraposição à expectativa do cientista, negativa em relação à recusa em realizar determinada tarefa ou ambas. Seja qual for o sentido de negativa, esse é o tipo de reação que ocorre em consequência de uma violação de expectativa, quando se trata da comparação de indivíduos (animais ou humanos) quanto a seus esforços e recompensas.

4 "During the evolution of cooperation it may have become critical for individuals to compare their own efforts and pay- offs with those of others." (Brosnan; De Waal, 2003, p. 297), tradução minha. 
Brosnan e de Waal (2003) citam a teoria de Fehr e Schmidt (1999), que explica a cooperação humana pela aversão à desigualdade nos limites do modelo da escolha racional. $\mathrm{O}$ que surge no texto, de passagem, nas referências, são precisamente as premissas que sustentam as noções de esforço, recompensa, cooperação e justiça. Para Fehr e Schmidt (1999, p. 819), justiça (fairness) pode ser "modelada como uma aversão autocentrada à desigualdade", ou seja, que pessoas resistem a resultados (recompensas) injustos, desde que aconteçam a elas e não a outros, o que afirmam usando como material empírico o comportamento de pessoas em jogos cooperativos e competitivos.

A explicação de comportamentos de pessoas concretas em situações concretas é estimada a partir de um modelo estatístico, baseado na teoria de jogos, tendo como premissa que as decisões das pessoas são motivadas pelo que denominam de escolha racional. São esses resultados que, supostamente, credenciam os autores a generalizar essas noções e afirmar, nessas bases, que o senso de justiça é um universal humano, de acordo com Henrich (2000) e Henrich et al. (2001), novamente em estudos sobre comportamento humano em jogos. A partir da análise das respostas previstas e efetivadas dos participantes em jogos, uma série de comportamentos humanos são descritos e extrapolados para os modelos explicativos de mercados e outros, no âmbito da economia, como o comportamento egoísta (aquele motivado unicamente pelo próprio retorno material) e o comportamento altruísta (indivíduos que frustram expectativas do modelo de escolha racional, visando recompensar aqueles que atuam de forma cooperativa). O estudo de Henrich (2001), em 15 sociedades de pequena escala segundo os autores estadunidenses ${ }^{5}$, concluiu que os padrões de comportamento no jogo são consistentes com os padrões culturais cotidianos em cada sociedade. É questionável, no entanto, a própria apreciação dos pesquisadores estrangeiros acerca da cultura dessas sociedades distintas das sociedades industrializadas. O trabalho de Henrich (2000) defende que a explicação do comportamento altruístico, distante do modelo canônico do Homo economicus (a escolha egoísta seria a forma racional de maximização de lucros), está baseada no desenvolvimento de impulsos emocionais, no julgamento de uma dada situação como injusta. E quais seriam os determinantes últimos de nossas emoções, senão os processos evolutivos que governam a distribuição de genes, os sempre inexoráveis elementos de nossa determinação sem saída, aqui reiterados por Henrich et al. (2001).

Retorno da longa digressão, depois de bem estabelecidas as premissas do texto: o senso de justiça, esse universal humano, envolve a apreciação de esforço e recompensa, em que o comportamento de cooperação aparece desde que represente uma apreciação vantajosa. Caso haja violação de expectativas na relação esforço despendido e recompensa recebida, pode haver frustração. $\mathrm{O}$ que o estudo introduz como elemento novo é que a cooperação seria não só um universal humano: ao ser encontrada em outros animais, é levantada a hipótese de que a aversão à desigualdade não seja uma exclusividade humana (WAAL; DAVIS, 2003).

O trabalho suscita questões acerca do estatuto natural da cooperação - ao verificar um procedimento classificado como cooperativo, essa característica adquire o sentido de natural enquanto algo contraposto a humano. Trata-se de abordagem desafiadora, se considerado o peso dos modelos explicativos baseados na ideia da competição entre espécies em um ambiente retratado como ameaçador. O estudo da cooperação, no âmbito da biologia e psicologia, tem história recente: o paradigma da teoria evolutiva, sustentado pela seleção natural, preconiza que indivíduos da mesma espécie e de espécies diferentes competem por recursos, e que características vantajosas para determinados indivíduos permitem que deixem mais descendentes, transmitindo essas características para sua prole. Decorre desse raciocínio

5 Algumas das sociedades descritas são Machiguenga (Peru), Mapuche (Chile/Argentina), Torguud (China/Mongólia), Achuar (Equador/Peru), Sangu (Tanzânia), Aché (Paraguai), Lamelara (Indonésia), Tsimané (Bolívia), Hadza (Tanzânia), Au (Papua Nova Guiné), Gnau (Papua Nova Guiné), Orma (Quênia). 
que o comportamento cooperativo contradiz o modelo da seleção natural, já que não é vantagem imediata para o indivíduo. Para De Waal e Davis (2003), a cooperação estável entre indivíduos não aparentados exige que as recompensas excedam aquelas obtidas através da ação individual, e o cálculo do custo/benefício pode ter ocorrido ou no passado evolutivo ou através da experiência de vida. Assim, o comportamento de cooperação estaria baseado em um cálculo (realizado pelos macacos?), guiado pelo conjunto de expectativas sobre a recompensa e a divisão de recursos (Uva? Pepino? Herança? Ou títulos no mercado de ações?).

Os resultados obtidos nos trabalhos de De Waal foram os já descritos no vídeo mencionado:

Here we demonstrate that a non human primate, the brown capuchin monkey (Cebus apella), responds negatively to unequal reward distribution in exchanges with a human experimenter. Monkeys refused to participate if they witnessed a conspecific obtain a more attractive reward for equal effort, an effect amplified if the partner received such a reward without any effort at all"6 (BROSNAN; DE WAAL, 2003, p. 297).

A partir desses resultados, o trabalho reafirma a hipótese de que estas reações sustentam uma origem evolutiva precoce da aversão à desigualdade. Como manda o figurino do modelo de ciência popperiana, uma hipótese científica deve ser testada, com o objetivo de ser falseada. Um complexo conjunto de experimentos foi montado pela equipe do estudo. Cada um dos experimentos é denominado como um diferente tipo de teste, e com seu respectivo experimento-controle. O teste de desigualdade foi o nome atribuído ao experimento em que os macacos recebem recompensas desiguais para mesmo esforço, retratado no vídeo mencionado. O teste de igualdade, por sua vez, foi aquele em que os dois macacos recebiam exclusivamente pepino após retornarem a pedra ao cientista (sem sinais de rejeição a esse alimento). No teste de controle de esforço, nenhuma pedra foi entregue aos macacos, apenas os alimentos - novamente, o da esquerda recebe pepinos, e o da direita uvas, apresentando reações similares. Por fim, no teste controle de alimento, um macaco é colocado sozinho na jaula, e na jaula vazia a seu lado são colocadas uvas, enquanto ele continua recebendo insossas fatias de pepino (BROSNAN; DE WAAL, 2003).

Entretanto, os testes realizados devem ser eles mesmos validados a partir de métodos estatísticos. Entram em jogo os testes estatísticos, requisitos para permitir as generalizações da hipótese proposta. Não me surpreende que um dos testes escolhidos tenha sido elaborado por expoentes da economia neoclássica, ainda que muito do que preconizaram tenha redundado mal para a própria ciência econômica. O primeiro teste de validação, exposto no texto estudado, foi elaborado por ninguém menos do que Milton Friedman, levando o seu nome: o teste de Friedman procura verificar se a média do desempenho na troca de pedras entre os quatro testes respeita a distribuição normal. O segundo teste foi o de comparações múltiplas de Tukey, afim de comparar o desempenho de trocas entre pares e, por fim, para comparar se houve diferença no desempenho das trocas entre a primeira e segunda metade de cada teste foram testadas através da distribuição exata da estatística de Wilcoxon (BROSNAN; DE WAAL, 2003). O aparato estatístico elaborado por Friedman, Tukey e Wilcoxon seria a autoridade capaz de assegurar se os testes desenhados por Brosnan e De

6 “Aqui, demonstramos que um primata não humano, o macacoprego marrom (Cebus apella) responde negativamente à distribuição desigual de recompensa em trocas com um experimentador humano. Macacos recusavam-se a participar se eles testemunhassem um coespecífico obtendo recompensa mais atraente para igual esforço, um efeito amplificado se o parceiro obtivesse tal recompensa sem qualquer esforço". (tradução minha). 
Waal são válidos, ou seja, a hipótese do senso de justiça como característica de primatas não humanos foi considerada válida a partir desses testes estatísticos. A discussão sobre as diversas concepções de justiça nas sociedades humanas e do significado de justiça numa sociedade de macacos-prego foi solapada pela produção dos índices estatísticos.

\section{A separação ser humano/natureza: fundamento da ciência reducionista}

Segundo Konder (1997), desde a Grécia antiga, com Heráclito, há uma resistência em pensar o mundo em termos de instabilidade, mudança, movimento, ou seja, em termos de conflito. Desde então, a metafísica defendida por Parmênides foi predominante em relação à dialética, afirmando que a essência profunda do ser era imutável, e que a mudança se dava apenas na superfície - uma visão que serve maravilhosamente bem à manutenção de privilégios das classes que estão no poder.

Um exemplo crucial para compreender a singularidade da lógica dialética é a distinção entre ser humano e natureza. Discutindo com Feuerbach, Marx e Engels (2007, p.31), discordam da oposição que o primeiro autor faz entre natureza e história: "o homem sempre teve diante de si uma natureza histórica e uma história natural"; assim, não haveria uma ciência natural pura dissociada da indústria e do comércio, ou seja, da produção, compreendida como trabalho e criação sensíveis. Não haveria natureza exterior, uma vez que o ser humano não é distinto da natureza. O ser humano é natureza, mas ao mesmo tempo não coincide com ela: ele é e não é, simultaneamente, o que constitui uma contradição. Só é possível falar em natureza na medida em que existe o ser humano, e só se pode falar em ser humano na medida em que existe natureza: um não existe sem o outro, e a sua existência é, ao mesmo tempo, a negação do outro. O elemento que faz com que ser humano e natureza não coincidam é o trabalho, ou a ação de transformar a natureza, para além de suas necessidades imediatas.

Com o trabalho, surge o ser humano, que não deixa de ser animal, de pertencer à natureza, mas por meio dele, deixa de pertencer inteiramente a ela, ao modificá-la. De acordo com Konder (1997, p.23), "Os animais agem apenas em função das necessidades imediatas e se guiam pelos instintos (que são forças naturais); o ser humano, contudo, é capaz de antecipar na sua cabeça os resultados das suas ações, é capaz de escolher os caminhos que vai seguir para tentar alcançar suas finalidades".

Para Ramos (2010, p.95):

[...] o ato de agir sobre a natureza transformando-a em função das necessidades humanas é o que se conhece como trabalho. Então, se a essência do homem não é dada a ele como dádiva divina ou natural, nem é algo que preceda a sua existência, ela é produzida pelos próprios homens na busca da satisfação de suas necessidades. O homem, então, assim se torna por meio do trabalho

A natureza só existe enquanto tal por ser assim concebida pelo ser humano: de outra forma, seria a sua mera continuidade enquanto animal humano. A natureza não é humana, existe independentemente do ser humano, porém, ao transformar a natureza, o ser humano se contrapõe a ela, por uma relação de exterioridade. O trabalho é responsável por fundar a relação sujeito-objeto, uma relação crucial ao pensarmos a ciência.

A expectativa de que o conhecimento científico traduza o real existente, externo à nossa consciência, é um dos grandes projetos do positivismo. O real observado, vivido ou suposto, ao ser descrito, passa a ter estatuto de verdade - a ciência assim se apresenta como um aspecto de verdade sustentado pelo empírico a que se refere. Entretanto, ao analisarmos a história, verificamos inúmeros casos em que o que era antes verdade acaba substituído por uma verdade nova, e, nesse processo de apreciação das verdades passadas, as ideias tidas 
como coerentes até pouco, desmoronam e caem no descrédito, ridicularizadas por sua pretensa ingenuidade frente à nova verdade erigida.

Stephen Jay Gould (1977) relata um exemplo referente às expectativas de cientistas no início do século XX, quanto à evolução humana. A teoria da evolução tornara-se hegemônica recentemente, e os esforços da comunidade científica eram envidados na busca pelos elos perdidos, hominídeos que apresentassem características intermediárias na evolução do ancestral primata do Homo sapiens. A expectativa de antropólogos e paleontólogos dos anos 1920, imersos nos preconceitos de classe que atribuem supremacia à atividade intelectual frente à manual, era de que houvesse ocorrido um aumento lento e gradual do tamanho do cérebro dos símios até o seu tamanho máximo, grande símbolo de inteligência, o ser humano. Ao desenvolver a característica mais distintiva do ser humano, a inteligência, a decorrência dessa capacidade intelectual foi o caminhar ereto. Qual não deve ter sido a surpresa e frustração desses cientistas ao se depararem com os fósseis de australopitecíneos, cujos cérebros, ainda que maiores que os dos símios, não tinham uma diferença de tamanho tão acentuada, porém caminhavam tão eretos quanto qualquer um de nós.

Foi Engels (2003) quem questionou esta expectativa idealista: propôs que os ancestrais símios, ao descerem das árvores, passaram a assumir uma postura mais ereta, o que permitiu liberar as mãos para atividades de manipulação ${ }^{7}$. O aumento da inteligência e a linguagem só vieram depois. As mãos são, assim, não apenas um instrumento de trabalho, mas também produto do próprio trabalho. O que teria feito com que a posição da primazia do cérebro para o surgimento do humano tenha sido dominante na ciência, a despeito da total ausência de sustentação empírica? De acordo com Gould (1977), a primazia do cérebro parecia tão óbvia e natural que foi aceita como um dom, ao invés de reconhecida como um preconceito social profundamente enraizado, relacionado à posição de classe dos pensadores profissionais e seus patrões. Nas palavras de Engels (2003, p. 275):

O rápido progresso da civilização foi atribuído exclusivamente à cabeça, ao desenvolvimento e à atividade do cérebro. Os homens acostumaram-se a explicar seus atos pelos seus pensamentos, em lugar de procurar essa explicação em suas necessidades (refletidas, naturalmente, na cabeça do homem, que assim adquire consciência delas). Foi assim que, com o transcurso do tempo, surgiu essa concepção idealista do mundo que dominou o cérebro dos homens, sobretudo a partir do desaparecimento do mundo antigo, e continua ainda a dominá-lo, a tal ponto que mesmo os naturalistas da escola darwiniana mais chegados ao materialismo são ainda incapazes de formar uma ideia clara acerca da origem do homem, pois essa mesma influência idealista lhes impede de ver o papel desempenhado aqui pelo trabalho.

O que procuro ilustrar com esse exemplo é que, partindo da premissa de que as circunstâncias fazem o ser humano, assim como seres humanos fazem suas circunstâncias, as condições em que vivemos interferem na forma como compreendemos o mundo. A ciência, como mais uma das criações humanas, que se propõe a entender a natureza, não está isenta dessas contradições. O que era uma verdade ontem, pode, a partir da investigação, ser ultrapassada amanhã, e, portanto, a ciência não pode ser tida como verdade inquestionável.

7 Engels foi extremamente influenciado pelas ideias de Lamarck, para quem as características físicas adquiridas por um esforço repetido de um indivíduo poderiam ser passada para seus descendentes (o que ficou conhecido como hipótese da herança de caracteres adquiridos). Levins e Lewontin (1985) propõem substituir a causalidade direta da herança de caracteres e substituir pela ação da seleção natural - a característica peculiar da forma de vida, a qual direcionou a seleção da mão, laringe e cérebro num feedback positivo, foram os processos de trabalho pelos quais ancestrais de humanos modificaram objetos naturais para tornarem-se adequados a seu uso. A ideia de feedback - ou de retroalimentação - é uma imagem interessante para se pensar dialeticamente na ação de um organismo sobre o ambiente e do próprio ambiente agindo sobre o indivíduo em transformação. 
Com isso não pretendemos ridicularizar o conhecimento científico, caindo num relativismo inerte. É evidente que diversas formas de apropriação da realidade puderam ser desenvolvidas, ainda que não possam ser chamadas de verdades, ou que, pelo menos, tenham o seu estatuto de verdade adjetivado de transitório. Porém, o que permite que a ciência possa assumir esse estatuto, muito particular, de verdades transitórias é o fato de possuir um método, ou seja, de descrever o caminho pelo qual se chegou a determinadas afirmações. $\mathrm{O}$ método é o elemento capaz de fazer da ciência um universal humano, ou seja, que qualquer ser humano possa, compartilhados os requisitos de linguagem, chegar a conclusões em comum a partir do raciocínio de outro ser humano com o qual não possui qualquer outra semelhança. Mais ainda: pode não só chegar às mesmas conclusões, mas inclusive questioná-las, propondo outras, a partir da problematização dos caminhos pelos quais o outro percorreu.

Ao discutir os termos ciência e científico, Gramsci (2013) recorda que eles assumem seu significado a partir de um grupo determinado de ciências, as ciências físicas e naturais. Todo método análogo ao método de pesquisa e exame dessas ciências, transformadas em ciências por excelência, foi chamado de "científico. Para o filósofo italiano, "não existem ciências por excelência e não existe um método por excelência, 'um método em si'. Toda pesquisa científica cria para si um método adequado, uma lógica própria, cuja generalidade e universalidade consiste apenas em ser 'conforme ao fim"” (GRAMSCI, 2013, p. 134-135).

É dessa maneira que, para Gramsci, a própria ciência é compreendida enquanto uma ideologia (ideologia aqui não enquanto uma falsa consciência, mas, sim, enquanto uma superestrutura). Para discutir essa questão, Gramsci questiona se a ciência pode dar (e como) a certeza da existência objetiva da chamada realidade exterior. Afirma que "é um erro exigir da ciência como tal a prova da objetividade do real, já que esta objetividade é uma concepção de mundo, uma filosofia, não podendo ser um dado científico" (2003, p.173). Gramsci afirma ser objetiva aquela realidade que é verificada por todos os humanos, independente de todo ponto de vista que seja puramente particular ou de grupo/classe. E afirma, coerente com sua própria concepção, que essa noção de objetividade, no fundo, é também uma concepção particular do mundo: uma ideologia.

Gramsci prossegue, colocando uma questão à ciência que se pretende objetiva:

[...] tudo isto que a ciência afirma é "objetivamente verdadeiro"? De modo definitivo? Se as verdades científicas fossem definitivas, a ciência teria deixado de existir enquanto tal, como investigação, como novas experiências, reduzindo-se a atividade científica à reprodução do que foi descoberto. O que não é verdade, para felicidade da ciência. Mas, se nem mesmo as verdades científicas são definitivas e peremptórias, também a ciência é uma categoria histórica (GRAMSCI, 2013, p.174).

A decorrência desse raciocínio, para Gramsci, é de que o interesse da ciência é menos a objetividade do real do que o próprio humano elaborando seus métodos de pesquisa, retificando seus instrumentos materiais e lógicos de discriminação e verificação: a cultura, a concepção do mundo, a relação entre homem e a realidade com a mediação da tecnologia. Tal apropriação da ciência enquanto cultura, ou seja, uma criação essencialmente humana, é consequência da historicidade da ciência, isto é, do seu movimento, do seu desenvolvimento dialético.

\section{Economia da injustiça e filosofia da natureza}

Ainda que eu não esteja em desacordo com a ideia de que o comportamento dos macacos estudados consista de uma rejeição à desigualdade, é imperioso discutir a circularidade da apreciação do caráter natural em questão. $\mathrm{O}$ modelo explicativo formulado 
no experimento parte de premissas muito caras à economia clássica (irmã mais velha do darwinismo, na sua versão original e na sua deformação como darwinismo social). A premissa de que a competição é inerente à natureza é fundamento do modelo da seleção natural, e a interpretação de comportamentos de animais é realizada à luz do conjunto de explicações da sociedade humana. Nessa perspectiva, dado que indivíduos são desiguais, suas escolhas são guiadas pela maximização de recompensas, frente ao esforço desenvolvido.

Por se tratar de uma apreciação sobre o próprio caráter do humano frente à natureza, e mais especificamente, de uma área de fronteira entre o que é essencialmente humano e o que é naturalizado entre outros seres vivos, é que esta discussão torna-se tão interessante quanto arriscada. Interessante porque traz problemas às definições dos limites do humano em contraposição à própria natureza: se existe julgamento entre primatas, o quanto de racional e o quanto de irracional/instintivo está presente no ato de julgar/apreciar? Certamente, é uma das questões que motiva trabalhos instigantes como os desenvolvidos por De Waal.

Há, entretanto, uma armadilha circular na acepção do natural: se concordarmos com Marx e Engels (2007, p.47) que a consciência humana não é pura, mas que é um produto social, ou seja, que "As ideias da classe dominante são, em cada época, as ideias dominantes, isto é, a classe que é a força material dominante da sociedade é, ao mesmo tempo, sua força espiritual dominante", então é preciso estar alerta para os interesses ao definir a economia em termos naturais e a natureza em termos econômicos liberais.

O modelo de um ser que julga e avalia esforços (será essa a percepção de um macaco-prego treinado sobre a devolução de pedras?) que tem recursos como recompensas (será que é essa a avaliação do macaco acerca de pepinos e uvas?) é muito próxima da expectativa do indivíduo autoconsciente que toma decisões baseadas no retorno financeiro, em um mercado guiado por expectativas racionais.

Mas esse indivíduo existe universalmente, ou trata-se de uma abstração generalizante do ser humano dominante no modo de produção capitalista? Justamente, nesse sentido é preciso pensar a economia na sua relação com a política, bem como a ciência na sua relação com a ideologia (ou enquanto uma forma de ideologia, segundo Gramsci, como concepção particular do mundo ao invés de falsa consciência). Ao fazê-lo, acreditamos que contribuímos para pensar numa forma de construção de conhecimento absolutamente comprometida com o ser humano, cuja universalidade seja compreendida por um conhecimento potencialmente acessível a todo e qualquer indivíduo (homem ou mulher), independente de grupo/classe.

A generalização de comportamentos humanos predizíveis a partir de modelos estatísticos é uma corrente forte da economia aplicada a jogos e da psicologia comportamental. Muitos dados têm sido gerados, colocando questões às fronteiras do que é intrinsecamente humano - aqui destacada a capacidade de julgamento. Porém, ao atribuir categorias do pensamento economicista neoclássico às reações investigadas em animais, a limitação do modelo explicativo é decorrente da própria visão de mundo dos cientistas e de suas referências, baseadas que estão no modelo esforço/recompensa, custo/benefício, que a própria teoria da evolução sugere fortemente.

Reiteramos, com isto, que nem invalidamos os esforços de compreensão do comportamento dos macacos-prego e, muito menos, a abrangência da teoria da evolução. Entretanto a separação entre sujeito e objeto, fulcral na atividade científica, nos traz armadilhas que, muitas vezes, precisam ser debatidas, a fim de podermos explicitar em que medida nossos pressupostos estão baseados em concepções particulares do mundo (ou ideologias).

Não há nada de ideológico em um macaco jogar uma fatia de pepino em uma cientista; afirmar, por sua vez, que essa reação negativa foi decorrência de um julgamento de pagamento desigual por um esforço realizado na sua comparação com um parceiro que recebeu alimento mais favorecido chega a tal acúmulo de implícitos que pode fazer 
inviabilizar uma apreciação não determinista da nossa assombrosa semelhança com os macacos-prego.

Ao qualificar a reação frente a uma situação pretensamente injusta (porque desigual) como um comportamento motivado por emoções sociais ou paixões segundo os economistas, em que medida os autores desqualificam a reação de seres humanos à injustiça enquanto algo secundário (porque não racional)? $\mathrm{O}$ que faz com que diferenciem a racionalidade do comportamento egoísta frente à irracionalidade das paixões presentes no comportamento altruísta, senão uma apreciação da economia clássica? O estatuto científico dessa construção ideológica se legitima a partir da validação dos testes estatísticos, porém quem delineia quais testes usar, o tamanho da amostra, e as conclusões obtidas não é a natureza analisada, mas, sim, os próprios cientistas.

Concluo as problematizações que procurei levantar com uma interpretação não cogitada pelo engenhoso experimento. Até mesmo um macaco-prego, um símio que possui encéfalo tão pequeno, parece desenvolver reações a um tratamento desigual. Isso me parece uma grande evidência do poder das construções ideológicas (superestruturais). Num contexto de grande intensidade do desenvolvimento no pensamento científico, alguns apostam mais na busca de explicações na natureza para legitimar a desigualdade em que vivemos do que questionar os privilégios de classe que sustentam os próprios preconceitos dos cientistas.

\section{Referências}

BROSNAN, S.F.; DE WAAL, F. B. M. Monkeys reject unequal pay. Nature, Londres, v.425, n.6955, p.297-299, Sept. 2003.

DE WAAL, F. B. M.; DAVIS, J.M. Capuchin cognitive ecology: cooperation based on projected returns. Neuropsychologia, Dallas, v.41, n.2, p.221-228, 2003.

ENGELS, F. Sobre o papel do trabalho na transformação do macaco em homem [1876]. In: ; MARX, K. (Orgs.). Obras escolhidas. São Paulo: Alfa-Omega, s/d, vol. 2. p. 267280.

FAIRCLOUGH, N. Discurso e Mudança Social. Brasília: UnB, 2001.

FEHR, E.; SCHMIDT, K.M. A theory of fairness, competition, and cooperation. Quarterly Journal of Economics, Cambridge, v.114, n.3, p. [817-868, Aug. 1999.

GOULD, S.J. Posture maketh the man. In: (Org.). Ever since Darwin. New York/London: Norton Paperback, 1977. p. 207-213.

GRAMSCI, A. Cadernos do Cárcere. Vol. 1. Rio de Janeiro: Civilização Brasileira, 2013.

HENRICH, J. Does culture matter in economic behavior? Ultimatum game bargaining among the Machiguenga of the Peruvian Amazon. The American Economic Review, Pittsburg, v.90, n.4, p.973-979, Sept. 2000.

HENRICH, J. et al. In search of Homo economicus: behavioral experiments in 15 small-scale societies. American Economic Review, Pittsburg, v.91, n. 2, p.73-78, May. 2001.

LEVINS, R.; LEWONTIN, R. The Dialectical Biologist. Cambridge/London: Harvard University Press, 1985. 
KONDER, L. O que é Dialética. São Paulo: Brasiliense, 1997.

MARX, K.; ENGELS, F. A Ideologia Alemã. São Paulo: Boitempo, 2007.

RAMOS, M. Trabalho, educação e correntes pedagógicas no Brasil: um estudo a partir dos trabalhadores técnicos da saúde. Rio de Janeiro: EPSJV/UFRJ, 2010.

Artigo recebido em 09/03/2014

Aceite em 26/03/2015 